\title{
NEUROTROPHIC REGULATION OF TWO PROPERTIES OF SKELETAL MUSCLE BY IMPULSE-DEPENDENT AND SPONTANEOUS ACETYLCHOLINE TRANSMISSION'
}

\author{
DANIEL B. DRACHMAN, ${ }^{2}$ ELIS F. STANLEY, ALAN PESTRONK, JOHN W. GRIFFIN AND \\ DONALD L. PRICE
}

Department of Neurology, Neuromuscular Unit, Johns Hopkins School of Medicine, Baltimore, Maryland 21205

Received July 10, 1981; Revised September 28, 1981; Accepted September 29, 1981

\begin{abstract}
In this study, we have evaluated the role of impulse-dependent and spontaneous acetylcholine (ACh) transmission in the neural regulation of two muscle properties: the resting membrane potential (RMP) and the number of extrajunctional ACh receptors.

Complete blockade of $\mathrm{ACh}$ transmission was produced by infusion of $\alpha$-bungarotoxin ( $\alpha$-BuTx) into the soleus muscles of rats in vivo via implanted osmotic pumps. Blockade of nerve impulse conduction was induced by prolonged treatment of the sciatic nerves of rats with tetrodotoxin (TTX). Control studies demonstrated that the pharmacological actions of $\alpha$-BuTx and TTX were highly specific, with no significant impairment of fast axonal transport or alterations in the morphology or physiology of the treated nerves.

ACh blockade using $\alpha$-BuTx produced a fall in the RMP that was identical to the effect of surgical denervation with respect to the time of onset, rate of development, and extent of change. Blockade of nerve impulses using TTX produced a similar but partial change in the RMP that began later and progressed more slowly than that of denervation.

Similarly, the increase of extrajunctional ACh receptors following $\alpha$-BuTx-induced blockade of ACh transmission was identical to that of surgical denervation. By contrast, the effect of nerve impulse block using TTX was less pronounced at equivalent time points.

Our findings indicate that specific pharmacological blockade of ACh transmission produces changes in the RMP and extrajunctional ACh receptors of skeletal muscle that are quantitalively equivalent to those of denervation. This suggests that $\mathrm{ACh}$ transmission itself mediates the nerve's trophic regulation of these muscle properties. Impulse-related $\mathrm{ACh}$ release and/or the muscle usage that it triggers account for only part of the regulatory effect; spontaneous $\mathrm{ACh}$ transmission (quantal and/or nonquantal) contributes the remainder. We suggest that nonquantal ACh release may represent the neurotrophic influence not fully accounted for in previous studies.
\end{abstract}

Motor innervation plays an important role in the regulation of many properties of skeletal muscle. Elimination of the influence of the nerve by surgical denervation results in a variety of changes in the physiological, biochemical, and structural properties of muscle fibers (Guth, 1968; Drachman, 1974; Gutmann, 19'6; Vrbova et al., 1978). Conversely, the motor nerve is thought to

\footnotetext{
${ }^{1}$ We would like to thank Dr. P. Talalay and Dr. J. J. Bray for reading the manuscript, R. N. Adams, K. F. Fahnestock, M. J. Peper, and C. Choy for technical assistance, and C. F. Barlow for help in preparation of the manuscript. This work was supported by National Institutes of Health Grants 5 PO1 NS10920 and 5 RO1 HD04817.

${ }^{2}$ To whom correspondence should be addressed at Department of Neurology, Johns Hopkins School of Medicine, 1721 E. Madison Street, Baltimore, MD 21205.
}

supply "trophic" influences that normally prevent these denervation changes. The question of how these influences of the nerve are mediated has been a matter of continuing controversy. Although ACh transmission and the muscle usage that it produces have been shown to play an important role (reviewed by Drachman et al., 1981; Thesleff and Sellin, 1980), it also has been suggested that unrelated factors (for example, materials carried by axonal transport) may participate as well (Fernandez and Ramirez, 1974; Ochs, 1974; Guth and Albuquerque, 1978; Guth et al., 1981).

In the present study, we have attempted to define the neural influences that regulate two such properties of skeletal muscle, the resting membrane potential (RMP) and the distribution of extrajunctional acetylcholine 
(ACh) receptors. These two properties change markedly following denervation: the RMP falls rapidly by approximately $15 \mathrm{mV}$ from a normal level of $-80 \mathrm{mV}$ (Ware et al., 1954; Albuquerque et al., 1971; Card, 1977; Stanley and Drachman, 1980); the extrajunctional ACh receptor density increases to a level several hundred times that of the innervated muscle (Axelsson and Thesleff, 1959; Miledi, 1960; Edwards, 1979; Fambrough, 1979).

Our experimental strategy has been based on the selective use of two specific neurotoxins: (1) $\alpha$-bungarotoxin $(\alpha-\mathrm{BuTx})$ to eliminate cholinergic transmission and (2) tetrodotoxin (TTX) to produce disuse by blocking nerve conduction. We have devised techniques for the application of the toxins to optimize blockade in the intact animal and have carried out detailed studies to ascertain the completeness and specificity of action of the neurotoxins as employed in the present experimental setting. Quantitative methods have been used to measure the changes in RMP and $\mathrm{ACh}$ receptors in order to compare the effects of pharmacological blockade with those of surgical denervation.

Our results lead to the conclusion that the neural regulation of the RMP and extrajunctional ACh receptors of skeletal muscle may be mediated entirely by cholinergic transmission. Both impulse-related and spontaneous release of $\mathrm{ACh}$ appear to have important roles in the regulatory process. The implications of our findings in terms of neurotrophic regulatory mechansims are considered below. Preliminary accounts of some of these findings have been reported previously (Pestronk et al., 1976b, 1980; Stanley and Drachman, 1979, 1980).

\section{Materials and Methods}

Experimental procedures were carried out on female Sprague-Dawley rats (180 to $200 \mathrm{gm}$ ) under chloral hydrate anesthesia $(400 \mathrm{mg} / \mathrm{kg})$.

$\alpha$-Bungarotoxin treatment (ACh blockade). These experiments were designed to measure the effects of blockade of ACh transmission on the RMP and extrajunctional ACh receptors of skeletal muscle. $\alpha$-BuTx obtained from the Miami Serpentarium was repurified by ion exchange chromatography using Whatman CM-32 columns. Neuromuscular blockade was initiated by injecting a loading dose of 3 or $8 \mu \mathrm{g}$ of $\alpha$-BuTx in $30 \mu \mathrm{l}$ of Ringer solution into the soleus muscle through a fine No. 30 needle. Blockade was maintained by continuous infusion of $\alpha$ BuTx in Ringer solution at a rate of $1.0 \mu \mathrm{l} / \mathrm{hr}$ (containing 0.2 or $0.4 \mu \mathrm{g} / \mu \mathrm{l}$ ) by means of Alzet osmotic infusion pumps implanted subcutaneously in the abdominal wall. The solution was delivered directly to the muscle via tapered polyethylene tubing sutured to the proximal tendon of the soleus. In short term experiments (up to 72 $\mathrm{hr}$ ), the higher loading and maintenance doses of $\alpha$-BuTx indicated above were used. In experiments of longer duration, the lower dose levels were used to avoid cumulative toxicity and to ensure survival of the animals.

In the studies of RMPs, one group of 20 rats was treated with $\alpha$-BuTx for 8 to $120 \mathrm{hr}$. In a second group of 19 animals, one soleus muscle was denervated by cutting the nerve to the soleus within $2 \mathrm{~mm}$ of its point of entry into the muscle using fine iridectomy scissors. Great care was taken not to disturb the blood supply or damage the muscle. The soleus muscles in the opposite legs of 11 of these animals served as unoperated controls. In 4 additional animals, the soleus was injected with $30 \mu \mathrm{l}$ of Ringer solution followed by pump infusion of Ringer solution at $1 \mu \mathrm{l} / \mathrm{hr}$ to control for the effect of infusion alone.

In the studies of extrajunctional $\mathrm{ACh}$ receptors, the treatment schedule was specially modified to permit the measurement of receptors by ${ }^{125} \mathrm{I}-\alpha-\mathrm{Bu}$ Tx binding after neuromuscular blockade with $\alpha$-BuTx. Injection and infusion of $\alpha$-BuTx were first carried out as above for 2 to 5 days. We confirmed the completeness of paralysis by observation of the soleus muscle under a dissecting microscope while stimulating the nerve to the soleus. The pumps then were removed, and neuromuscular blockade was maintained as follows: a single intramuscular injection of $3 \mu \mathrm{g}$ of $\alpha$-BuTx was given immediately, followed $24 \mathrm{hr}$ later by a final injection of $0.6 \mu \mathrm{g}$ of ${ }^{125} \mathrm{I}$-labeled $\alpha$ BuTx. The measurement of extrajunctional ACh receptors is possible after this treatment because their rapid turnover (Berg and Hall, 1975b; Linden and Fambrough, 1979) results in replacement of most $\alpha$-BuTx-blocked extrajunctional receptors by newly incorporated receptors within $48 \mathrm{hr}$. Because the $\alpha$-BuTx injected on the final day of ACh blockade was ${ }^{125}$ I labeled, it not only served to maintain the transmission block but also specifically labeled the $\mathrm{ACh}$ receptors present at that time (Stanley and Drachman, 1978). The blocked ACh receptors remaining at the end of the experiment thus were counted together with those subsequently labeled in vitro with ${ }^{125} \mathrm{I}-\alpha$-BuTx (see below).

Three groups of animals were used for comparison. In the first group, the soleus muscle was denervated by surgical section of the sciatic nerve in the midthigh. The second group was both denervated and treated with $\alpha$ BuTx; injections of $3 \mu \mathrm{g}$ of $\alpha$-BuTx were given on days 0 and 2 or 5 , and $0.6 \mu \mathrm{g}$ of ${ }^{125} \mathrm{I}-\alpha$-BuTx was given 1 day after the last dose as in the experimental animals. In the third (control) group, polyethylene catheters filled with Ringer solution were sutured to the soleus muscle and, in some cases, were connected to Alzet pumps.

To evaluate the specificity of action of chronically administered $\alpha-B u^{\prime} T x$, the following control studies were carried out: (1) intracellular microelectrode recordings were made in 18 muscles treated with $\alpha$-BuTx for up to $72 \mathrm{hr}$. (2) Light microscopic studies of neuromuscular junctions were made in 12 soleus muscles treated with $\alpha$-BuTx for 2 to 7 days. At the end of the treatment period, the muscles were quick-frozen in isopentane cooled with solid $\mathrm{CO}_{2}$, sectioned in a cryostat, and stained for the combined demonstration of nerve terminals and acetylcholinesterase as described previously (Pestronk and Drachman, 1978). (3) Electron microscopic studies were carried out in 7 soleus muscles treated with $\alpha$-BuTx for 2 or 5 days and in 2 control soleus muscles. At the end of the $\alpha$-BuTx infusion, the rats were killed by intraaortic perfusion with Ringer solution, followed by a fixative solution of $5 \%$ glutaraldehyde in $0.1 \mathrm{~m}$ phosphate buffer, $\mathrm{pH}$ 7.3. Endplate-containing segments of soleus muscles were located by staining for cholinesterase (Karnovsky and Roots, 1964). These segments were postfixed with $1 \%$ osmium tetroxide for $2 \mathrm{hr}$, dehydrated, and 
embedded in Epon 812. 'Thin sections were cut on a Sorvall MT2B ultramicrotome, placed on Formvarcoated grids, stained with uranyl citrate and lead acetate, and examined with an AE801 electron microscope. Fiftyfour junctions of $\alpha$-BuTx-treated muscles and 27 control junctions were photographed and examined. (4) Measurement of fast axonal transport was carried out in 6 $\alpha$-BuTx treated rats by the radiometric methods described below. In 5 additional animals, $\alpha$-BuTx was injected into the mid-sciatic nerve to determine whether it directly impedes axonal transport.

Tetrodotoxin treatment (muscle disuse). Impulse conduction was blocked in the sciatic nerve by subperineurial injection of tetrodotoxin (TTX) (Sankyo) as described previously (Pestronk et al., 1976b). TTX (2 $\mu \mathrm{g}$ in $2 \mu \mathrm{l}$ of Ringer solution) was injected into the surgically exposed sciatic nerve at the midthigh level by means of a glass micropipette coupled to a micrometer-driven syringe mounted on a micromanipulator. Nerve conduction block developed within $10 \mathrm{~min}$ and usually remained complete for $48 \mathrm{hr}$.

By means of repeated injections at 48-hr intervals, paralysis was maintained for up to 7 days without nerve damage. Just before each repeat injection of TTX and at the termination of each experiment, the blockade was tested by electrical stimulation of the nerve above the injection site. If the blockade was incomplete, the animals were discarded.

RMPs were measured in the soleus muscles of 22 rats treated with TTX for 1 to 7 days. Eighteen animals, denervated by surgical section of the sciatic nerve in the midthigh at the same intervals prior to RMP measurement, also were examined in this study. Controls consisted of the opposite soleus muscle of 18 denervated or TTX-treated animals either untreated (15 muscles) or treated with injections of Ringer solution (3 muscles).

Extrajunctional $\mathrm{ACh}$ receptors were determined in the extensor digitorum longus (EDL) and soleus muscles of 17 rats treated with TTX for 4 or 7 days. Twenty-five animals denervated by sciatic nerve section, 5 animals denervated and given TTX injections into the distal nerve stump, and 9 animals treated with intraneural injections of Ringer solution also were used in this experiment for extrajunctional $\mathrm{ACh}$ receptor determination.

Control studies to ascertain the efficacy and specificity of the TTX treatment were carried out in three groups of TTX-treated animals. In the first group of rats, intracellular recordings of miniature endplate potentials (mepps) and evoked endplate potentials (epps) were made after 1 to 7 days of TTX treatment. The second group of animals was used for light microscopy of treated nerves. The sciatic and soleus nerves of rats treated with TTX for 7 days and of the 6 rats treated with Ringer solution for 7 days were embedded in Epon. One-micrometer-thick sections were stained with toluidine blue, coded, and examined microscopically by three of us without knowledge of the prior treatment. The third group of 11 animals treated with TTX for $2 \mathrm{hr}$ to 7 days was used for measurement of fast axonal transport (see below).

Resting membrane potential measurement. RMPs were measured in the exposed soleus muscles in vivo using glass microelectrodes filled with $3 \mathbf{M ~} \mathrm{KCl}$ and having tip resistances of 5 to 20 megohms. The electrodes were connected to a W-P Instruments (M701) amplifier with a unity gain. The output of the amplifier was fed into a sensitive electrometer (Keithley 6012B) for measurement of RMPs and also was displayed on a Tektronix $(510 \mathrm{~N})$ storage oscilloscope for measurement of miniature endplate potentials (mepps). Microelectrodes were rejected if there was an increase in tip resistance of 4 megohrus or more during the course of recording. The tip potentials of 15 typical microelectrodes averaged 0.8 $\mathrm{mV}$ and were invariably less than $2.5 \mathrm{mV}$. RMPs were recorded from the anterior aspect of the soleus muscle. An incision was made through the skin on the lateral side of the calf, and the biceps femoris then was separated from the tibialis anterior muscle. The biceps femoris was reflected to expose the anterior aspect of the soleus. Immediately after exposure, the soleus was bathed in fresh rat serum, and a pool of serum was formed over the muscle by raising the skin flaps on either side. After 5 min of equilibration, the temperature of the serum pool stabilized at between 32 and $35^{\circ} \mathrm{C}$. Where serum was used to bathe the muscle, the RMPs were found to be higher and more stable than when the muscle was bathed in Ringer solution (Kernan, 1963).

All recordings were made from the region of the muscle containing the endplates, as it has been suggested that the earliest change in RMP after denervation may occur at the junctional region of the muscle fiber (Albuquerque et al., 1971). In experiments where mepps were present, the occurrence and rise times of mepps $(<1.5 \mathrm{msec}$, onset to peak) were used as a guide to the endplate regions of the muscle. Where there were no mepps (long term denervation or postsynaptic blockade), we relied on knowledge of the location of the endplate region in the muscle, which was first determined by mapping cholinesterase staining in a series of excised soleus muscles (Stanley and Drachman, 1980). Only RMPs from surface fibers were measured, as it has been shown that deeper fibers have a higher mean RMP (Card, 1977).

Extrajunctional $A C h$ receptor determinations. Muscles were teased longitudinally into three or four pieces, pinned at resting length, and incubated for 3 to $4 \mathrm{hr}$ at $37^{\circ} \mathrm{C}$ in modified Ham's F-12 culture medium containing 0.1 to $0.3 \mu \mathrm{g}$ of ${ }^{125} \mathrm{I}-\alpha-\mathrm{BuTx} / \mathrm{ml}$ (specific activity, 2 to 5 $\times 10^{4} \mathrm{Ci} \mathrm{mol}^{-1}$ ) as previously described (Pestronk et al., $1976 \mathrm{a}, \mathrm{b})$. The muscles then were washed thoroughly, fixed in $4 \%$ glutaraldehyde, and stained for acetylcholinesterase. Junction-free muscle strips were dissected further under the stereomicroscope into small bundles of 10 to 100 fibers, and the number and length of fibers in each bundle were determined. The radioactivity due to bound ${ }^{125} \mathrm{I}-\alpha-\mathrm{Bu}$ Tx was measured in a Gamma counter. Transverse sections of frozen muscles stained with hematoxylin and eosin were used to compute average fiber diameters. Results are expressed as ACh receptor sites per $\mu \mathrm{m}^{2}$ of surface membrane (mean $\pm \mathrm{SE}$ ).

Axonal transport. In order to determine whether $\alpha$ BuTx or TTX might interfere with axonal transport, we carried out measurements of fast axonal transport of radiolabeled proteins and glycoproteins in the sciatic nerves of rats treated with each of the neurotoxins. The 
radioactive precursors used in these studies included $\left[{ }^{3} \mathrm{H}\right]$ leucine, $\left[{ }^{3} \mathrm{H}\right]$ fucose, and $\left[{ }^{35} \mathrm{~S}\right]$ methionine. The precursor solution was injected directly into the ventral horn of the lumbar spinal cord by means of a glass micropipette mounted on a micrometer-driven syringe as previously described (Griffin et al., 1976, 1981). Following injection, the sciatic nerve bed or rectal temperature was maintained at $37^{\circ} \mathrm{C}$ by a temperature regulator (Yellow Springs Instrument Co. model 73) and heat lamp. After an interval of 4 to $24 \mathrm{hr}$ to permit axonal transport, the animals were killed as previously described. The sciatic nerves and ventral roots were dissected in continuity and divided into 3 -mm segments. Each segment was digested in $2 \mathrm{~N} \mathrm{NaOH}$ at $60^{\circ} \mathrm{C}$, neutralized, and dissolved in Aquasol (New England Nuclear) scintillation counting medium. Counting was done in a Beckman LS150 scintillation counter. The results, expressed as counts per min per $3-\mathrm{mm}$ nerve segment, were plotted against the position along the nerve, given in millimeters (Figs. 1 and 2). The short duration (4- to 8-hr) experiments were used to determine the rate of fast transport by measuring the distance to the point at which the leading edge of the curve fell below 2 SD above the mean base line nontransported radioactivity in the nerve. Mean rates of transport are expressed as millimeters per day $\left(\mathrm{mm} \mathrm{d}^{-1}\right) \pm \mathrm{SE}$. The long term (24-hr) experiments were used to test whether any transported material was held up at the site of intraneural injection of $\alpha$-BuTx or TTX.

\section{Results}

\section{Effects of neurotoxins}

We first examined the effects of prolonged $\alpha$-BuTx and TTX treatments on neuromuscular function and structure.

$\alpha$-Bungarotoxin. $\alpha$-BuTx treatment produced complete neuromuscular blockade within $1 / 2$ to $1 \frac{1 / 2}{\mathrm{hr}}$ after the initial intramuscular injection and was maintained throughout the duration of the infusion. Nerve stimulation failed to elicit detectable contractions as observed with the stereomicroscope. Neither mepps nor epps could be recorded with intracellular microelectrodes.

Axonal transport of incorporated $\left[{ }^{35} \mathrm{~S}\right]$ methionine was normal in rate $\left(389 \pm 18 \mathrm{~mm} \mathrm{~d}^{-1}\right)$ and did not differ significantly from the control side $\left(403 \pm 38 \mathrm{~mm} \mathrm{~d}^{-1}\right)$ (Fig. 1a). With the intraneural administration of the toxin, there was no retention of transported radioactivity at the site of injection (Fig. $1 b$ ).

The morphology of the neuromuscular junctions of soleus muscles treated with $\alpha$-BuTx for 2 to 7 days was examined by light microscopy of material stained for axons and acetylcholinesterase and measured as previously described (Pestronk and Drachman, 1978). There were no morphological differences between $\alpha$-BuTxtreated and control junctions (Fig. $2 a$ ). The mean endplate length was $40 \pm 2$ (SE) $\mu \mathrm{m}$ in $\alpha$-BuTx-treated muscles and $39 \pm 2 \mu \mathrm{m}$ in controls; the number of nerve terminal branch points was $3.4 \pm 0.2$ /endplate in $\alpha$-BuTxtreated muscles and $3.5 \pm 0.1$ /endplate in controls. In muscles denervated for the same period of time, the nerve terminals had degenerated completely.

Electron micrographs of the neuromuscular junctions
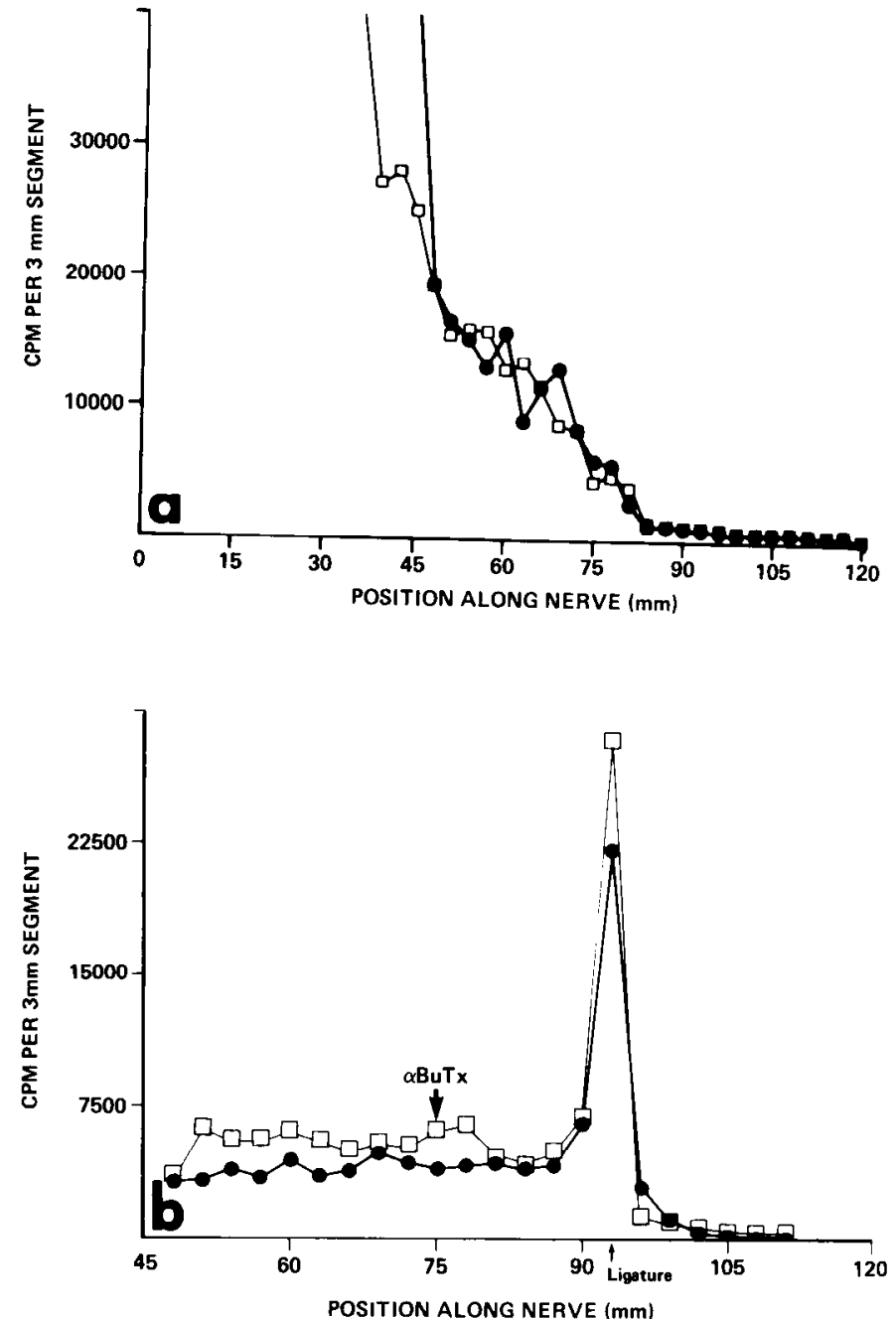

Figure 1. Effect of $\alpha$-BuTx on fast axonal transport of $\left[{ }^{35} \mathrm{~S}\right]$ methionine-labeled proteins in rat sciatic nerves. $\alpha, \alpha-\mathrm{Bu} \mathrm{Tx}$ was infused into the soleus muscle as described in the text. $\square$, $\alpha$-BuTx-infused side; 9 , opposite untreated control side. Nerves were removed $5 \mathrm{hr}$ after intraspinal injection of $\left[{ }^{35} \mathrm{~S}\right]$ methionine. The curves represent mean values for 3 animals. There were no differences in the rates of fast transport or the forms of the transport curves in the $\alpha$-BuTx-treated and control sides. $b$, Transport curves of rat sciatic nerves injected with $\alpha$-BuTx ( $\square$ ) or Ringer solution (O) at the position of the arrow. The nerves were ligated distal to the site of injection, and transported material was allowed to accumulate for $24 \mathrm{hr}$. Note that the amount of radioactivity transported to the ligature is comparable in the two nerves and that there is no accumulation proximal to the site of injection.

of soleus muscles treated for 2 or 5 days with $\alpha$-BuTx infusions showed no abnormalities. The nerve terminals, apposition of pre- and postsynaptic structures, and postsynaptic folds were all identical to controls (Fig. 3).

Tetrodotoxin. Injection of TTX into the sciatic nerve resulted in complete, sustained block of nerve conduction across the treated region. The sciatic nerve was stimulated, and electrical recordings were made from the surface of the soleus and EDL muscles in vivo while the muscles were observed under a stereomicroscope. In animals treated with TTX for 2 to 7 days, no mechanical or electromyographic responses could be detected from 

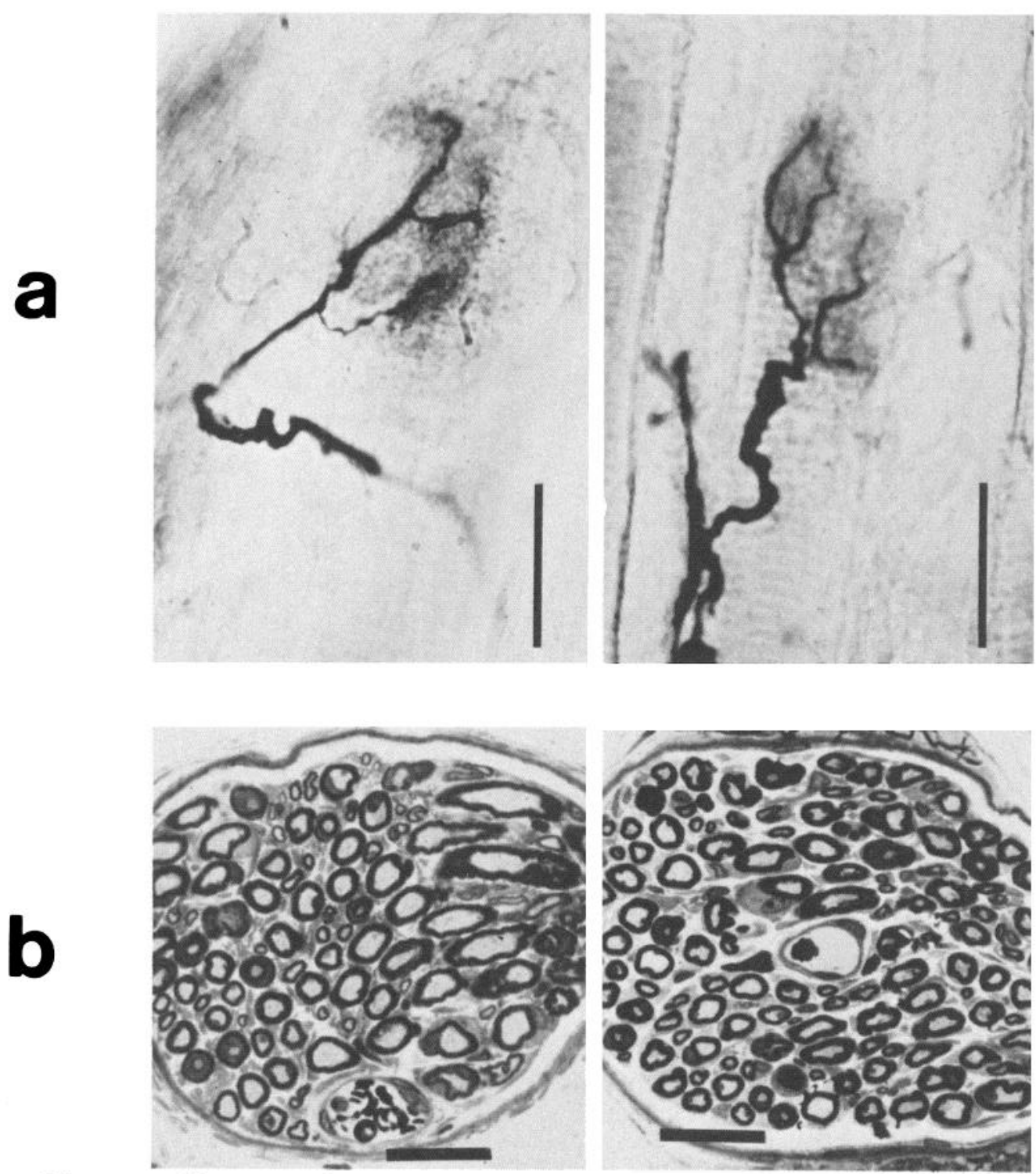

Figure 2. $a$, Neuromuscular junctions from normal and $\alpha$-BuTx-treated soleus muscles. The black silver-stained nerve terminals end within the gray areas stained for cholinesterase. Typical junctions from a normal control animal (left) and from muscle treated with $\alpha$-BuTx for 7 days (right) are shown. There was no difference in terminal size or morphology in normal and $\alpha$-BuTx-treated muscles. $B a r=25 \mu \mathrm{m}$. $b$, Soleus nerves after sciatic nerve injection with Ringer solution (left) and TTX (right). In each case, the nerves were treated for 7 days. A few fibers showed Wallerian degeneration in each nerve. Sections were stained with toluidine blue. $B a r=25 \mu \mathrm{m}$.

the muscles following a stimulus proximal to the blocked region of the nerve. A stimulus distal to the blocked region of the nerve, however, resulted in a brisk contraction and a normal muscle action potential. In the muscles of TTX-treated animals, mepps were recorded in a proportion $(69 \%)$ of muscle fibers similar to that of the controls $(73 \%)$. Further study of mepps was done in vitro using excised muscles immersed in oxygenated Trowell's T8 medium. Seven days of TTX treatment did not reduce the mepp frequency (soleus, $2.0 \pm 0.03 \mathrm{~s}^{-1}$; EDL, $2.4 \pm$ $0.27 \mathrm{~s}^{-1}$ ) or amplitude (soleus, $0.37 \pm 0.03 \mathrm{mV}$; EDL, 0.46 $\pm 0.05 \mathrm{mV}$, corrected to $-75 \mathrm{mV} \mathrm{RMP}$ ) recorded at $22^{\circ} \mathrm{C}$.

Fast axonal transport of incorporated $\left[{ }^{3} \mathrm{H}\right]$ leucine, $\left[{ }^{35} \mathrm{~S}\right]$ methionine, or $\left[{ }^{3} \mathrm{H}\right]$ fucose was measured in rats treated with TTX for 7 days. The transport rate through the region of injection was normal $\left(387 \pm 26 \mathrm{~mm} \mathrm{~d}^{-1}\right)$ and equal to that of the control side $\left(396 \pm 16 \mathrm{~mm} \mathrm{~d}^{-1}\right)$. The form of transport curves was not altered by TTX treatment nor was there holdup of transported radioactivity at the site of injection (Fig. 4).

The effect of TTX treatment on the morphology of 7day TTX-injected and Ringer-injected nerves was examined by light microscopy. No morphological differences were found in the sciatic nerve or its branches to EDL and soleus; only occasional degenerating axons could be identified after either treatment (Fig. $2 b$ ).

\section{Effects of treatments on muscle RMPs}

The normal RMP in the rat soleus muscle measured in vivo was $79.4 \pm$ (SD) $3.0 \mathrm{mV}$ in 684 muscle fibers from 

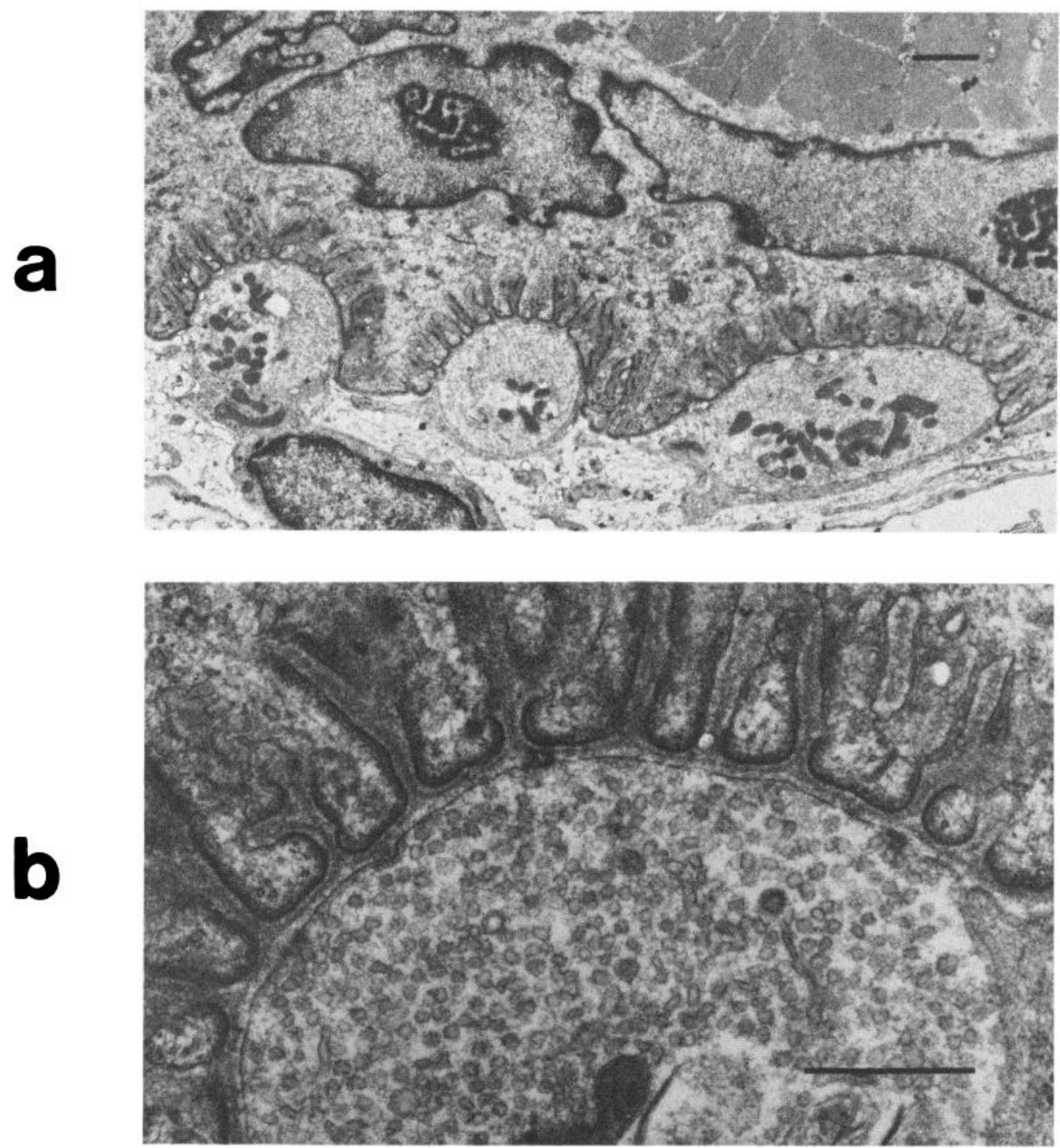

Figure 3. Electron micrographs of a typical neuromuscular junction of soleus muscle treated for 5 days with $\alpha$-BuTx. Note the normal morphology of nerve terminals and postsynaptic regions. $a$, Low power view: magnification $\times 8,760$. $B a r=1 \mu \mathrm{m}$. $b$, High power view of nerve terminal: magnification $\times 44,000$. Bar $=0.45 \mu \mathrm{m}$.

34 untreated muscles. Surgical denervation, leaving a 5$\mathrm{mm}$ nerve stump, resulted in a fall in the RMP which began at 18 to $24 \mathrm{hr}$ and reached a plateau of about -65 $\mathrm{mV}$ at 36 to $42 \mathrm{hr}$ (Table I; Fig. 5).

The result of $\alpha$-BuTx infusion was identical to that of surgical denervation: the RMP began to fall at 18 to 24 $\mathrm{hr}$ after the onset of treatment, declined maximally to $-65 \mathrm{mV}$ at 36 to $42 \mathrm{hr}$, and remained at that level for at least $80 \mathrm{hr}$ (Table I; Fig. 5). Muscles treated with infusions of Ringer solution showed no change in RMP as compared to untreated controls. Thus, the curves of RMP change after denervation and, after $\alpha$-BuTx treatment, were virtually superimposable (Table I; Fig. 5).

Similarly, TTX treatment produced a decrease in the RMPs of soleus muscle fibers. However, the change began between 48 and $72 \mathrm{hr}$, which was later than that following midthigh nerve section. It did not reach the maximum fall to $-65 \mathrm{mV}$ until about 7 days (Table II; Fig. 6).

\section{Effects of treatments on extrajunctional ACh receptors}

Surgical denervation resulted in a marked increase of extrajunctional $\mathrm{ACh}$ receptors in both the EDL and soleus muscles. The rise was greater at 7 days than at 4 days (Figs. 7 and 8 ).

$\alpha$-BuTx treatment also produced an increase in extrajunctional ACh receptors above control levels (Fig. 7). More important, comparison of the extrajunctional ACh receptor density in the $\alpha$-BuTx-treated muscles and the two groups of denervated muscles showed no significant differences. Thus, $\alpha$-BuTx infusion reproduced the effect of denervation with respect to extrajunctional $\mathrm{ACh}$ receptors. In control experiments, the surgical manipulations involved in the infusion did not increase the level of extrajunctional ACh receptors significantly as compared to the untreated controls. Furthermore, the $\alpha$ BuTx did not appear to exert a direct effect on muscle independent of its interference with neuromuscular 


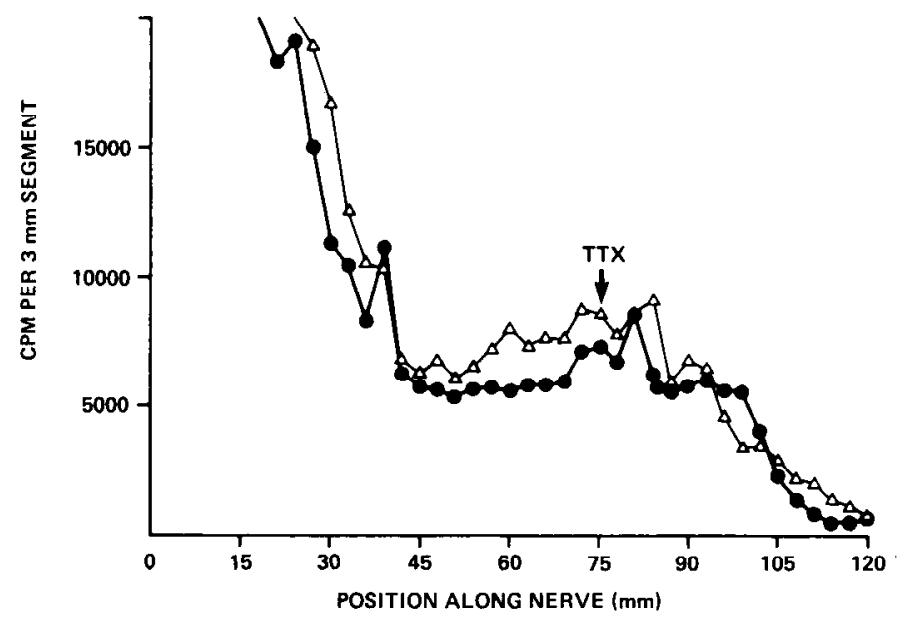

Figure 4. Effect of intrancural TTX injection on fast axonal transport of $\left[{ }^{35} \mathrm{~S}\right]$ methionine-labeled proteins in rat sciatic nerve. $\triangle$, Nerve treated with TTX for 5 days at the position of the arrow; , opposite control side injected with Ringer solution for 5 days. Nerves were removed $7 \mathrm{hr}$ after intraspinal injection of $\left[{ }^{35} \mathrm{~S}\right]$ methionine. There was no difference in the rate of fast transport or in the form of the transport curves. Transported protein did not accumulate at the site of injection.

TABLE I

Effect of $\alpha-B u T x$ and denervation on the RMP

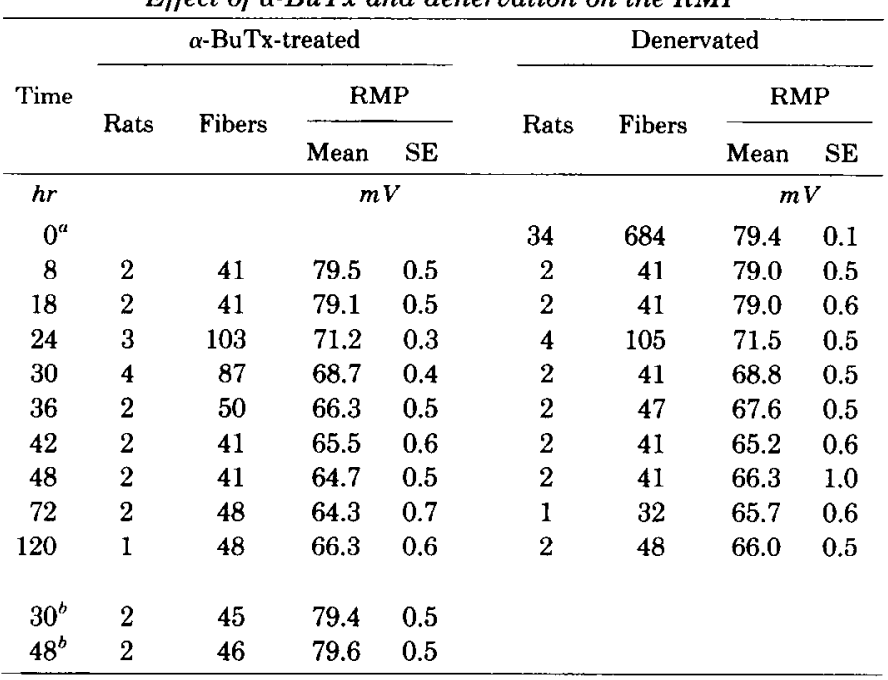

${ }^{a}$ Pooled untreated controls.

${ }^{o}$ Ringer-treated controls.

transmission, since $\alpha$-BuTx treatment plus denervation produced levels of extrajunctional ACh receptors similar to those of either treatment alone (Fig. 7).

Similarly, TTX treatment produced a denervation-like increase of extrajunctional ACh receptors in the EDL and soleus muscles at both 4 and 7 days (Fig. $8, a$ and $b$ ). However, the levels of ACh receptors in the TTX-treated muscles were significantly lower than those of the denervated muscles at both time points. The injection procedure itself could not account for the increase in extrajunctional ACh receptors in the TTX-treated animals, as there was no change following subperineurial injections of control Ringer solution. TTX had no effect on the levels of ACh receptors in addition to that of denervation, since treatment with TTX plus denervation resulted in an increase of $\mathrm{ACh}$ receptors similar to that of denervation alone (Fig. 8, $a$ and $b$ ).

\section{Discussion}

The main findings in the present investigation show that: (1) blockade of neuromuscular transmission with $\alpha$-BuTx results in changes in the RMP and extrajunctional ACh receptors of skeletal muscle that are quantitatively equivalent to those of surgical denervation and (2) blockade of nerve impulse conduction with TTX leads to changes in the two muscle properties tested that are similar to, but less pronounced than, those of denervation.

As in any pharmacological study, the interpretation of these findings depends critically on the specificity of action of the agents used. The two neurotoxins used in these experiments, $\alpha$-Bu'Tx and TTX, are highly potent and selective biological agents known to interfere with specific steps in the processes of neuromuscular excitation. We have evaluated the physiological effects of each

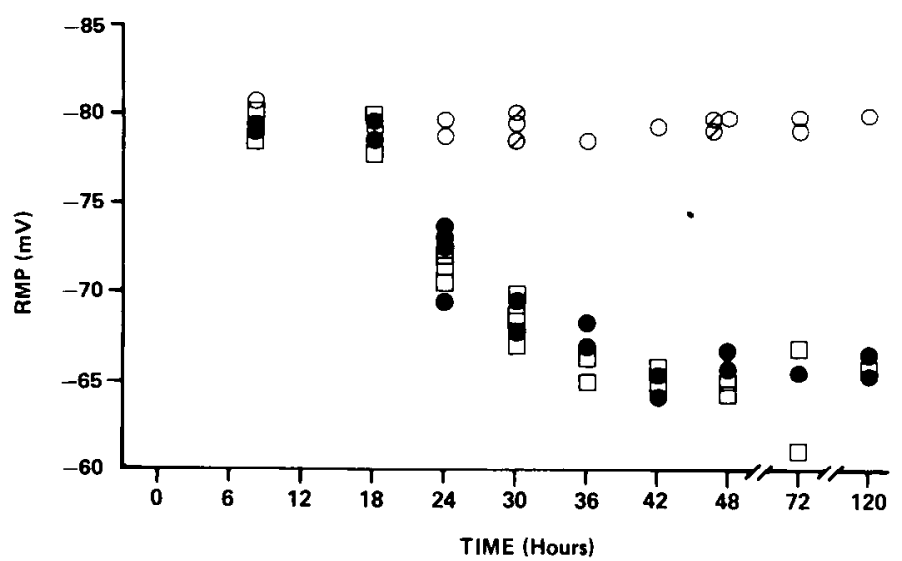

Figure 5. Effect of $\alpha$-BuTx treatment and denervation on RMPs of soleus muscles. $O$, Untreated control muscles; $\varnothing$, Ringer-treated control muscles; $\odot$, denervated muscles; $\square, \alpha$ BuTx-treated muscles. Note that the time course of the fall in RMP was virtually identical in the $\alpha$-BuTX-treated and denervated muscles. Each point represents the mean RMP of 20 fibers in a single muscle.

TABLE II

Effect of intraneural TTX injection and denervation on the RMP

\begin{tabular}{|c|c|c|c|c|c|c|c|c|}
\hline \multirow{3}{*}{ Time } & \multicolumn{4}{|c|}{ TTX-injected ${ }^{a}$} & \multicolumn{4}{|c|}{ Denervated } \\
\hline & \multirow{2}{*}{ Rats } & \multirow{2}{*}{ Fibers } & \multicolumn{2}{|c|}{ RMP } & \multirow{2}{*}{ Rats } & \multirow{2}{*}{ Fibers } & \multicolumn{2}{|c|}{ RMP } \\
\hline & & & Mean & $\mathrm{SE}$ & & & Mean & $\mathrm{SE}$ \\
\hline & \multicolumn{6}{|c|}{$m V$} & \multicolumn{2}{|c|}{$m V$} \\
\hline $0^{b}$ & & & & & 34 & 684 & 79.4 & 0.1 \\
\hline $12 \mathrm{hr}$ & & & & & 2 & 40 & 79.8 & 0.5 \\
\hline $24 \mathrm{hr}$ & 4 & 52 & 78.8 & 0.3 & 2 & 40 & 73.8 & 0.5 \\
\hline $36 \mathrm{hr}$ & 2 & 24 & 78.4 & 0.6 & 2 & 37 & 69.5 & 1.0 \\
\hline $48 \mathrm{hr}$ & 4 & 54 & 78.7 & 0.5 & 2 & 40 & 64.3 & 0.6 \\
\hline 3 days & 4 & 61 & 73.0 & 0.5 & 2 & 60 & 66.0 & 0.5 \\
\hline 4 days & 4 & 62 & 69.5 & 0.7 & 2 & 41 & 65.1 & 0.6 \\
\hline 5 days & 1 & 20 & 71.5 & 1.0 & & & & \\
\hline 6 days & & & & & 3 & 60 & 65.1 & 0.4 \\
\hline 7 days & 3 & 107 & 64.4 & 0.4 & 3 & 135 & 65.2 & 0.3 \\
\hline 6 days $^{c}$ & 3 & 62 & 81.1 & 0.4 & & & & \\
\hline
\end{tabular}


toxin under the particular conditions of the present experiments in order to determine the completeness and specificity of their actions. Detailed examinations of the structure and function of the treated nerves and neuromuscular junctions have been carried out to rule out unexpected damaging effects of the toxins.

$\alpha$-Bungarotoxin. Numerous studies have confirmed the specificity of action of $\alpha$-BuTx in blocking ACh receptors of skeletal muscle (Miledi and Potter, 1971; Changeux et al., 1970; Lee, 1972). $\alpha$-BuTx has no known

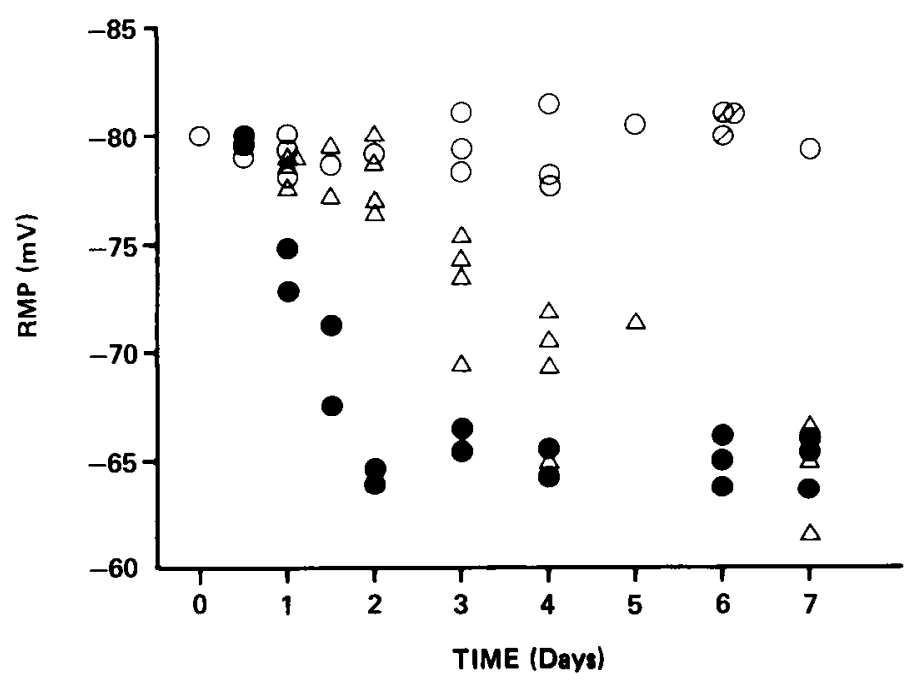

Figure 6. Effect of TTX blockade of nerve conduction on RMPs of soleus muscles. $O$, Untreated control muscles; $\varnothing$, Ringer-treated muscles; $\triangle$, TTX-blocked muscles; - denervated muscles. Note that TTX treatment resulted in a fall of the RMP that began later and fell more gradually than after denervation. Each point represents the mean RMP of 7 to 20 fibers in a single muscle.

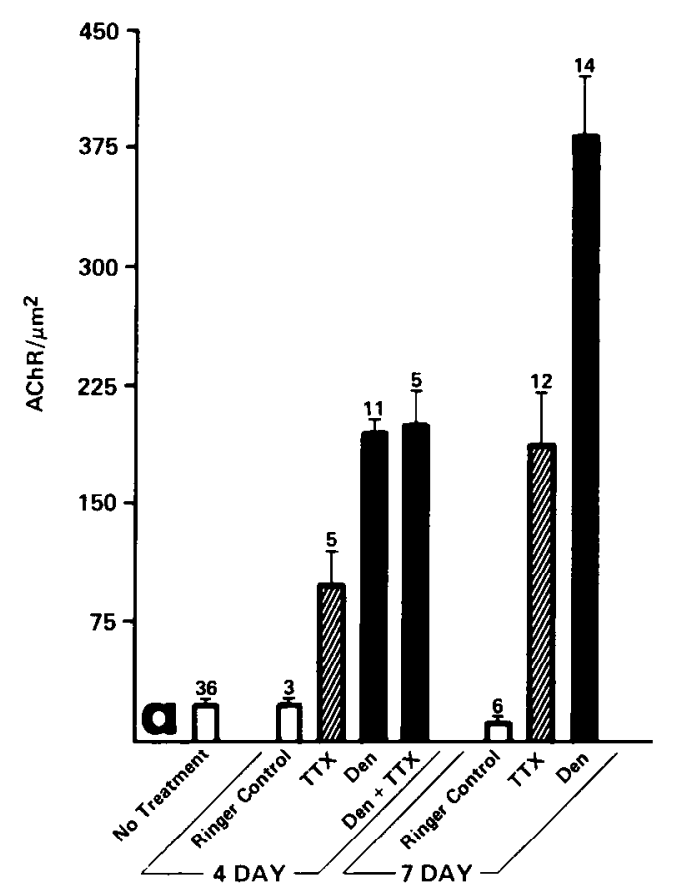

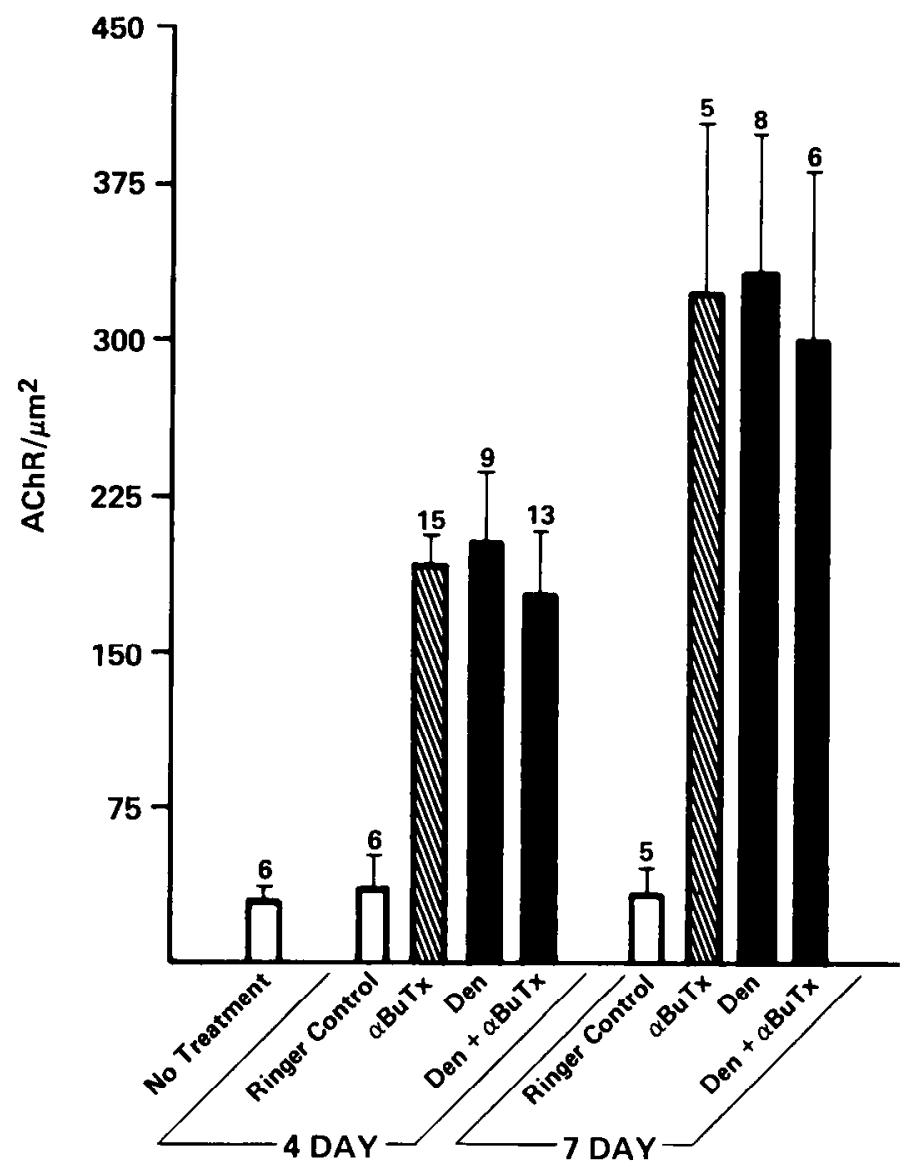

Figure 7. Effect of $\alpha$-BuTx treatment on extrajunctional $\mathrm{ACh}$ receptors $(A C h R)$ of rat soleus muscles. Note that the increase of $\mathrm{ACh}$ receptors after $\alpha$-BuTx treatment was equivalent to that after denervation (Den) at both the 4- and 7-day time points.

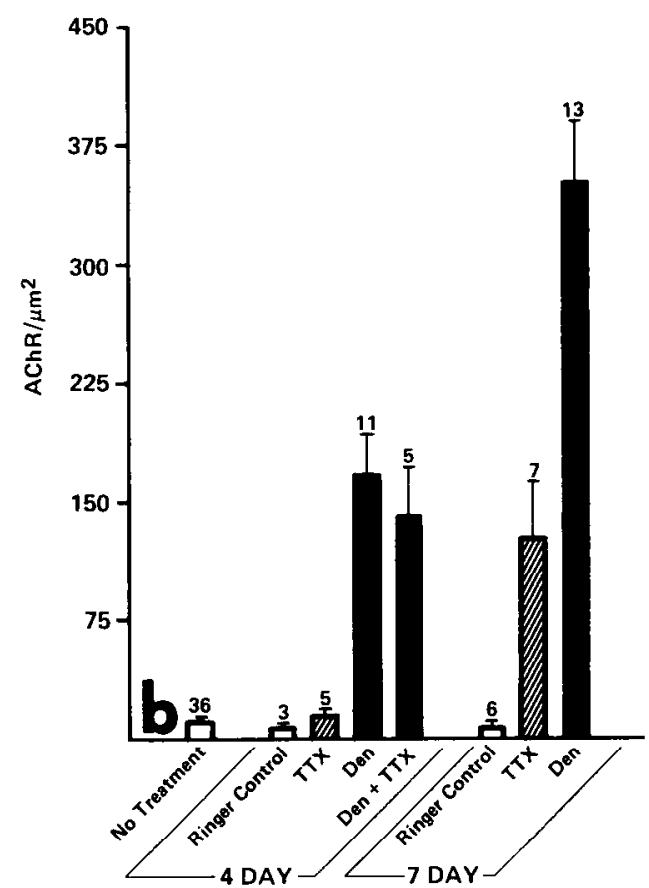

Figure 8. Effect of TTX blockade of nerve conduction on extrajunctional ACh receptors $(A C h R)$ of rat muscles. $a$, Soleus muscle; $b$, extensor digitorum longus muscle. Note that TTX produced a significant increase of ACh receptors and that the effect of denervation (Den) was greater than that of TTX at both 4 and 7 days. 
inhibitory action on the release of ACh by the motor nerve or nerve terminal (Miledi et al., 1978), although presynaptic binding has been suggested by electron microscopy (Lentz et al., 1977).

Although the binding of $\alpha$-BuTx to ACh receptors is virtually irreversible, previous attempts to produce lasting cholinergic blockade by intramuscular injections of the toxin have been disappointing because partial recovery of neuromuscular transmission occurs rapidly (Chang et al., 1975; Fertuck et al., 1975; Pestronk and Drachman, 1978). We therefore devised a method of continuous local intramuscular infusion of $\alpha$-BuTx which maintains a persistent blockade of $\mathrm{ACh}$ transmission as documented by the absence of mepps and the lack of electrophysiological or mechanical response to motor nerve stimulation. Prolonged infusion of $\alpha$-BuTx by this method did not damage the motor nerve terminals histologically or ultrastructurally. Fast axonal transport was not affected by intramuscular infusion or intraneural injection of $\alpha$ BuTx. Thus, as used in the present investigation, $\alpha$-BuTx infusion appears to be an effective method of producing both specific and continuous blockade of cholinergic transmission. By virtue of its postsynaptic action at the $\mathrm{ACh}$ receptor site, it can intcrcept all $\mathrm{ACh}$ transmission (both quantal and nonquantal). Because of its specificity, it is highly improbable that $\alpha$-BuTx could interfere with the transport, delivery, or action of hypothetical "trophic" agents other than ACh.

Tetrodotoxin. TTX has been shown to interfere with the conduction of electrical impulses in excitable membranes by blocking sodium conductance channels (Evans, 1972). In this study, it was injected intraneurally, resulting in complete blockade of nerve conduction at the site of application, while allowing the distal portion of the nerve to function normally. We have been able to maintain nerve blockade for a prolonged period of time by injecting TTX repeatedly without significantly damaging the nerves or nerve terminals morphologically. Furthermore, TTX blockade does not interfere with axonal transport of radiolabeled proteins and glycoproteins across the site of injection or throughout the length of the nerve. Finally, the distal portion of the axon and the nerve terminals remain functionally intact as judged by their ability to release $\mathrm{ACh}$ spontaneously and in response to impulses. Based on these observations, TTX blockade fulfills the criteria for pure muscle disuse: nerve impulses (and impulse-related ACh release and muscle usage) are eliminated without structural or functional damage to the motor nerves or neuromuscular junctions.

Blockade of ACh transmission: Effects on RMP and $A C h$ receptors. It was first necessary to establish the time course of the change in RMP following denervation, since previous reports have given conflicting results (Albuquerque et al., 1971; Card, 1977). Using an in vivo recording technique, we found that the RMP began to fall 18 to $24 \mathrm{hr}$ after nerve section (with a very short nerve stump) and achieved a maximum change of $15 \mathrm{mV}$ at 36 to $42 \mathrm{hr}$ (Stanley and Drachman, 1980) in agreement with Card (1977). This time course has proven highly consistent through seven separate sets of experiments using 117 animals.

Blockade of cholinergic transmission by $\alpha$-BuTx infu- sion resulted in changes in the RMP that faithfully reproduced the pattern of surgical denervation. The curves of RMP changes in $\alpha$-BuTx-treated and denervated muscles were virtually superimposable throughout their entire time course (see "Results"; Fig. 5).

Similarly, the increase of extrajunctional ACh receptors corresponded closely in $\alpha$-BuTx-treated and denervated muscles at the two time periods examined. These changes could not be attributed to the experimental manipulations, since control infusions of Ringer solution or surgical implantation of polyethylene catheters had no such effects. Further, the $\alpha$-BuTx did not have a direct effect on the muscles independent of ACh receptor blockade, since the combination of denervation plus $\alpha$-BuTx treatment did not result in a higher level of $\mathrm{ACh}$ receptors than denervation alone.

These findings now demonstrate that the effects of cholinergic blockade are quantitatively equivalent to those of surgical denervation with respect to the two neurally regulated properties of muscle examined. Our results are in general agreement with those of earlier studies of the RMP and extrajunctional ACh receptors (Berg and Hall, 1975a; Chang et al., 1975; Mathers and Thesleff, 1978; Pestronk and Drachman, 1978; Tonge, 1978), though the previous reports did not establish the quantitative completeness of the effects. In some studies, the use of methods that produced partial ACh blockade gave results that were similar to those obtained in the present experiments but were less pronounced than the effects of denervation (Chang et al., 1975; Pestronk et al., 1976a; Pestronk and Drachman, 1978; Tonge, 1978). In one report (Berg and Hall, 1975a), systemic administration of postsynaptic blocking agents to rats resulted in large effects on ACh receptors and RMPs. However, the heroic methods necessary to sustain the paralyzed animals precluded the accumulation of sufficient data to permit quantitative conclusion regarding the completeness of the effects. In our investigations, the method of intramuscular $\alpha$-BuTx infusion produced continuous local blockade of ACh transmission; its simplicity permitted the use of relatively large numbers of animals, and the reproducibility of the methods of measurement of RMP and ACh receptors allowed quantitative comparison with the effects of surgical denervation.

TTX blockade of nerve impulses: Effects on RMP and ACh receptors. TTX blockade of impulse conduction resulted in changes in both the RMP and the extrajunctional ACh receptors of skeletal muscles similar to those of denervation but less marked in degree and/or slower in the time course of development. The RMP began to fall at 48 to $72 \mathrm{hr}$ after beginning TTX treatment, which is much later than the 18- to 24-hr onset observed after denervation. The rate of decline of the RMP was slower than that following denervation; it eventually attained a maximum decrease of $15 \mathrm{mV}$ at about 7 days of TTX treatment, while the RMP of denervated muscles reached this level at $48 \mathrm{hr}$. Similarly, extrajunctional ACh receptors increased after TTX nerve blockade. However, the increase was less marked, as compared with the denervated muscles, at both 4 and 7 days. Reports from several laboratories have confirmed the partial denervation-like effects of TTX blockade on these 
and other properties of muscle (Lavoie et al., 1976; Pestronk et al., 1976b; Mills et al., 1978).

The results of our TTX experiments are consistent with two other lines of evidence that indicate that nerve impulses and muscle usage have an important but partial role in the neural regulation of skeletal muscle properties. First, several reports have shown that electrical stimulation is effective in preventing or reversing certain denervation changes (Jones and Vrbova, 1970; Drachman and Witzke, 1972; Iømo and Rosenthal, 1972; Purves and Sakmann, 1974; Westgaard, 1975). For example, when stimulation was applied directly to the denervated hemidiaphragms of rats in imitation of the normal phrenic nerve impulse pattern, the increase of extrajunctional ACh sensitivity was largely, but incompletely, prevented (Drachman and Witzke, 1972). Second, "nerve stump" experiments have shown that some influence independent of nerve impulses or muscle activity remains in the distal stump of a severed motor nerve and is capable of delaying the onset of certain denervation changes. The onset of fibrillations (Luco and Eyzaguirre, 1955), the fall in the RMP (Locke and Solomon, 1967; Albuquerque et al., 1971; Stanley and Drachman, 1980), and the increase in extrajunctional ACh receptors (Uchitel and Robbins, 1978) occur later in muscles with longer nerve stumps than in those with nerves sectioned close to the muscle. Since nerve section renders the denervated muscles inactive regardless of the stump length, this indicates that some factor other than muscle usage must account for the difference in timing. These experiments do not specify the nature of the factor, which we suggest may be continued spontaneous ACh leakage (see below).

The role of ACh transmission and its impulse-directed and spontaneous components. Our observations show that elimination of ACh transmission alone is equivalent to surgical denervation with respect to its effects on the muscle properties examined. The simplest interpretation of these findings is that the loss of ACh transmission is sufficient to account for the changes in the RMP and extrajunctional ACh receptors that follow denervation. Further, this suggests that ACh transmission normally mediates the motor nerve's influence on the RMP and extrajunctional ACh receptors.

The separate contributions of impulse-dependent and spontaneously released components of $\mathrm{ACh}$ transmission also may be inferred from our data. As noted above, blockade of nerve impulses by TTX produced incomplete denervation-like effects on the RMP and extrajunctional $\mathrm{ACh}$ receptors. Since elimination of all $\mathrm{ACh}$ transmission by $\alpha$-Bu'l'x resulted in complete denervation-like effects, while blockade of its impulse-dependent fraction produced only partial effects, the difference may be attributed to the spontaneously released component of ACh.

According to present concepts, spontaneous release of ACh from motor nerve terminals occurs in both quantal (Fatt and Katz, 1952) and nonquantal forms (Potter, 1970; Katz and Miledi, 1977). Far more ACh is believed to be liberated by nonquantal leakage than by spontaneous quantal release (Potter, 1970; Katz and Miledi, 1977). The relative contributions of each of these forms of spontaneous ACh release in regulating skeletal muscle properties have not yet been defined. However, we now have preliminary evidence that nonquantal ACh release has an important role in the regulation of the RMP. As described above, the onset and time course of the changes in RMP produced by denervation and $\alpha$-BuTx treatment were virtually identical. If cessation of $\mathrm{ACh}$ transmission is responsible for the change in RMP, this would predict that ACh transmission stops at about the same time after either treatment. We have found that $\alpha$-BuTx blocks cholinergic transmission by about $1 \frac{1 / 2}{\mathrm{hr}}$ after injection. Nerve section results in immediate cessation of nerve impulses (and therefore of impulse-dependent $\mathrm{ACh}$ release). Spontaneous quantal ACh release (mepps) persists for approximately $12 \mathrm{hr}$. Preliminary studies indicate that the bulk of spontaneous ACh release-presumably the nonquantal form-stops earlier than the mepps, i.e., within a few hours after close nerve section (Stanley and Drachman, 1981). This suggests that impulse-dependent and nonquantal spontaneous forms of $\mathrm{ACh}$ release are most important in the regulation of the RMP, while the role of spontaneous quantal ACh release is not yet clear.

Experiments using botulinum toxin suggest that both forms of spontaneous $\mathrm{ACh}$ release may be involved in the regulation of extrajunctional ACh receptors. Botulinum toxin has been shown to block nearly all quantal ACh release, including both the impulse-related and the spontaneous components (Brooks, 1956; Kao et al., 1976; Pestronk et al., 1976a; Cull-Candy et al., 1976). Its effect on nonquantal ACh release is not yet known, though a substantial proportion of spontaneous ACh release is not blocked by the toxin. Chronic botulinum treatment results in an increase of extrajunctional ACh receptors similar to, but less pronounced than, that of denervation (Pestronk et al., 1976a; Simpson, 1977; Mathers and Thesleff, 1978) but greater than that of disuse (Pestronk et al., 1976b). The fact that the effect of botulinum is less than that of surgical denervation suggests that nonquantal ACh release left unblocked by botulinum toxin plays a role in the mediation of the nerve's regulatory effect. Additional support for this view is provided by experiments showing that the combination of botulinum toxin and a postsynaptic blocking agent, which could interfere with transmission of nonquantally released $\mathrm{ACh}$, produces a greater change in ACh receptors than does botulinum alone (Mathers and Thesleff, 1978). On the other hand, the fact that the effect of botulinum toxin is greater than that produced by impulse blockade with TTX may be due to its additional interference with spontaneous quantal $\mathrm{ACh}$ release.

These observations lead to the conclusion that spontaneous ACh release plays an important partial role in the regulation of both the RMP and the extrajunctional ACh receptors of skeletal muscle, though further studies are needed to define the precise contribution of the quantally and nonquantally released components.

It has been suggested previously that hypothetical trophic substances delivered to skeletal muscles by motor nerves may regulate the RMP, extrajunctional ACh receptors, and other muscle properties (Albuquerque et al., 1972; Fernandez and Ramirez, 1974; Guth and Albuquerque, 1978; Guth et al., 1981; Ochs, 1974). For example $\alpha$ BuTx might theoretically block the neural release or muscle uptake of a trophic factor other than ACh. While this possibility cannot logically be excluded entirely, the exquisite specificity of action of $\alpha$-BuTx detailed above makes such actions highly improbable. Based on the present results, there seems to be no need to postulate 
trophic mediators other than ACh to account for the neural regulation of the muscle properties studied in this investigation. It is tempting to speculate that spontaneous nonquantal ACh release constitutes the previously unaccounted for "neurotrophic factor."

\section{Conclusions}

Specific pharmacological blockade of ACh transmission produced changes in the RMP and extrajunctional ACh receptors of skeletal muscle that were quantitatively equivalent to those of denervation. We therefore postulate that $\mathrm{ACh}$ transmission itself mediates the nerve's trophic regulation of these properties. Impulse-related $\mathrm{ACh}$ release and/or the muscle usage that it triggers can account for only part of the regulatory effect of the motor nerve. The remainder is attributed to transmission of spontaneously released $\mathrm{ACh}$; the relative contributions of the quantally and nonquantally released forms require further definition. The fact that both the RMP and the extrajunctional ACh receptors respond similarly to changes in cholinergic transmission provides mutual support for these observations. However, this does not imply that all neurally regulated properties of muscle are influenced identically by ACh transmission. The factors that regulate each such property must be evaluated individually. Future studies need to be directed toward learning more about the muscle's side of the relationship, in order to determine how cholinergic transmission regulates a complex range of biochemical and physiological responses on the part of the muscle.

\section{References}

Albuquerque, E. X., F. T. Schuh, and F. C. Kauffman (1971) Early membrane depolarization of the fast mammalian muscle after denervation. Pfluegers Arch. 328: 36-50.

Albuquerque, E. X., J. E. Warnick, J. R. Tasse, and F. M. Sansone (1972) Effects of vinblastine and colchicine on neural regulation of the fast and slow skeletal muscle of the rat. Exp. Neurol. 37: 607-634.

Axelsson, J., and S. Thesleff (1959) A study of supersensitivity in denervated mammalian skeletal muscle. J. Physiol. (Lond.) 147: 178-193

Berg, D. K., and Z. W. Hall (1975a) Increased extrajunctional sensitivity produced by chronic post-synaptic neuromuscular blockade. J. Physiol. (Lond.) 244: 659-676.

Berg, D. K., and Z. W. Hall (1975b) Loss of $\alpha$-bungarotoxin from junctional and extrajunctional receptors in rat diaphragm in vivo and in organ culture. J. Physiol. (Lond.) 252: 771-789.

Brooks, V. (1956) An intracellular study of the action of repetitive nerve volleys and of botulinum toxin on miniature endplate potentials. J. Physiol. (Lond.) 134: 264-277.

Card, D. J. (1977) Denervation: Sequence of neuromuscular degenerative changes in rats and the effect of stimulation. Exp. Neurol. 54: 251-265.

Chang, C. C., S. -T. Chuang, and M. C. Huang (1975) Effects of chronic treatment with various neuromuscular blocking agents on the number and distribution of acetylcholine receptors in the rat diaphragm. J. Physiol. (Lond.) 250: 161-173.

Changeux, J. -P., M. Kasai, and C. -Y. Lee (1970) Use of a snake venom to characterize the cholinergic receptor protein. Proc. Natl. Acad. Sci. U. S. A. 67: 1242-1247.

Cull-Candy, S. G., H. Lund, and S. Thesleff (1976) Effects of botulinum toxin on neuromuscular transmission in the rat. $\mathrm{J}$. Physiol. (Lond.) 260: 177-203.
Drachman, D. B., ed. (1974) Trophic functions of the neuron. Ann. N. Y. Acad. Sci. 228: 1-143.

Drachman, D. B., and F. Witzke (1972) Trophic regulation of acetylcholine sensitivity of muscle. Effect of electrical stimulation. Science 176: 514-516.

Drachman, D. B., A. Pestronk, and E. F. Stanley (1981) Neurotrophic interaction between nerves and muscles: Role of acetylcholine. In Diseases of the Motor Unit, E. L. Schotland, ed., Houghton Mifflin, New York, in press.

Edwards, C. (1979) The effects of innervation on the properties of acetylcholine receptors in muscle. Neuroscience 4: 565-584.

Evans, M. H. (1972) Tetrodotoxin, saxitoxin and related substances: Their applications in neurobiology. Int. Rev. Neurobiol. 15: 83-166.

Fambrough, D. M. (1979) Control of acetylcholine receptors in skeletal muscle. Physiol. Rev. 59: 165-227.

Fatt, P., and B. Katz (1952) Spontaneous subthreshold activity at motor nerve endings. J. Physiol. (Lond.) 117: 109-128.

Fernandez, H. L., and B. U. Ramirez (1974) Muscle fibrillation induced by blockade of axoplasmic transport in motor nerves. Brain Res. 79: 385-395.

Fertuck, H. C., W. Woodward, and M. M. Salpeter (1975) In vivo recovery of muscle contraction after $\alpha$-bungarotoxin binding. J. Cell Biol. 66: 209-213.

Griffin, J. W., D. B. Drachman, and D. L. Price (1976) Fast axonal transport in motor nerve regeneration. J. Neurobiol. 7: 355-370.

Griffin, J. W., D. L. Price, D. B. Drachman, and J. Morris (1981) Incorporation of axonally transported glycoproteins into axolemma during nerve regeneration. J. Cell Biol. 88: 205-215.

Guth, L. (1968) "Trophic" influences of nerve on muscle. Physiol. Rev. 48: 645-687.

Guth, L., and E. X. Albuquerque (1978) The neurotrophic regulation of resting membrane potential and extrajunctional acetylcholine sensitivity in mammalian skeletal muscle. Physiol. Bohemoslov. 27: 401-413.

Guth, L., V. F. Kemerer, 'I. A. Samaras, J. E. Warnick, and E. $\mathrm{X}$. Albuquerque (1981) The roles of disuse and loss of neurotrophic function in denervation atrophy of skeletal muscle. Exp. Neurol. 73: 20-36.

Gutmann, E. (1976) Neurotrophic relations. Annu. Rev. Physiol. 38: 177-216.

Jones, R., and G. Vrbova (1970) Effect of muscle activity on denervation by hypersensitivity. J. Physiol. (Iond.) 210: 144-145.

Kao, I., D. B. Drachman, and D. L. Price (1976) Botulinum toxin: Mechanisin of presynaptic blockade. Science 193: 1256-1258.

Karnovsky, M. J., and L. Roots (1964) A "direct coloring" thiocholine method for cholinesterases. J. Histochem. Cytochem. 12: 219-221.

Katz, B., and R. Miledi (1977) Transmitter leakage from motor nerve endings. Proc. R. Soc. Lond. (Biol.) 196: 159-172.

Kernan, R. P. (1963) Resting potential of isolated rat muscles measured in plasma. Nature 200: 474-475.

Lavoie, P. A., B. Collier, and A. Tenenhouse (1976) Comparison of $\alpha$-bungarotoxin binding to skeletal muscles after inactivity or denervation. Nature 260: 349-350.

Lee, C. Y. (1972) Chemistry and pharmacology of polypeptide toxins in snake venoms. Annu. Rev. Pharmacol. 12: 265-286.

Lentz, T. L., J. E. Mazurkiewicz, and J. Rosenthal (1977) Cytochemical localization of acetylcholine receptors at the neuromuscular junction by means of horseradish peroxidaselabeled $\alpha$-bungarotoxin. Brain Res. 132: 423-442.

Linden, D. C., and D. M. Fambrough (1979) Biosynthesis and degradation of acetylcholine receptors in rat skeletal muscles. Effects of electrical stimulation. Neuroscience 4: 527-538.

Locke, S., and H. C. Solomon (1967) Relation of resting poten- 
tial of rat gastrocnemius and soleus muscles to innervation, activity and the Na-K pump. J. Exp. Zool. 166: 377-386.

Lømo, T., and J. Rosenthal (1972) Control of ACh sensitivity by muscle activity in the rat. J. Physiol. (Lond.) 221: 493-513.

Luco, J. V., and C. Eyzaguirre (1955) Fibrillation and hypersensitivity to $\mathrm{ACh}$ in denervated muscle: Effect of length of degenerating nerve fibers. J. Neurophysiol. 18: 65-73.

Mathers, D. A., and S. Thesleff (1978) Studies on neurotrophic regulation of murine skeletal muscle. J. Physiol. (Lond.) 282: $105-114$.

Miledi, R. (1960) The ACh sensitivity of frog muscle fibers after complete or partial denervation. J. Physiol. (Lond.) 151: 1-23.

Miledi, R., and L. T. Potter (1971) Acetylcholine receptors in muscle fibers. Nature 233: 599-603.

Miledi, R., P. C. Molenaar, and R. L. Polak (1978) $\alpha$-Bungarotoxin enhances transmitter "released" at the neuromuscular junction. Nature 272: 641-643.

Mills, R. G., J. J. Bray, and J. J. Hubbard (1978) Effects of inactivity on membrane potentials in rat muscle. Brain Res. 150: $607-610$.

Ochs, S. (1974) Systems of material transport in nerve fibers (axoplasmic transport) related to nerve function and trophic control. Ann. N. Y. Acad. Sci. 228: 202-223.

Pestronk, A., and D. B. Drachman (1978) Motor nerve sprouting and acetylcholine receptors. Science 199: 1223-1225.

Pestronk, A., D. B. Drachman, and J. W. Griffin (1976a) Effect of botulinum toxin on trophic regulation of acetylcholine receptors. Nature 264: 787-789.

Pestronk, A., D. B. Drachman, and J. W. Griffin (1976b) Disuse of muscle: Effect on extrajunctional acetylcholine receptors. Nature 260: 352-358.

Pestronk, A., D. B. Drachman, E. F. Stanley, D. L. Price, and J. W. Griffin (1980) Cholinergic transmission regulates extrajunctional acetylcholine receptors. Exp. Neurol. 70: 690-696.

Potter, L. T. (1970) Synthesis, storage and release of ${ }^{14} \mathrm{C}$-acetylcholine in isolated rat diaphragm muscles. J. Physiol. (Lond.) 206: 145-166.

Purves, D., and B. Sakmann (1974) The effect of contractile activity on fibrillation and extrajunctional acetylcholine-sensitivity in rat muscle maintained in organ culture. J. Physiol. (Lond.) 237: 157-182.

Simpson, L. L. (1977) The effect of acute and chronic botulinum toxin treatment on receptor number, receptor distribution, and tissue sensitivity in rat diaphragm. J. Pharmacol. Exp. Ther. 200: 343-351.

Stanley, E. F., and D. B. Drachman (1978) Effect of myasthenic immunoglobulin on acetylcholine receptors of intact neuromuscular junctions. Science 200: 1285-1287.

Stanley, E. F., and D. B. Drachman (1979) Effect of disuse on the resting membrane potential of skeletal muscle. Exp. Neurol. 64: 321-324.

Stanley, E. F., and D. B. Drachman (1980a) Denervation and the time course of resting membrane potential changes in skeletal muscle in vivo. Exp. Neurol. 69: 253-259.

Stanley, E. F., and D. B. Drachman (1980b) The role of ACh transmission in the neural regulation of muscle resting membrane potential. Soc. Neurosci. Abstr. 6: 384 .

Stanley, E. F., and D. B. Drachman (1981) Non-quantal ACh release in the mouse diaphragm: Effects of denervation and botulinum toxin. Soc. Neurosci. Abstr. 7: 440.

Thesleff, S., and L. C. Sellin (1980) Denervation supersensitivity. Trends Neurosci. 4: 122-126.

Tonge, D. A. (1978) Prolonged effects of a post-synaptic blocking fraction of Naja siamensis venom on skeletal muscle of the mouse. Q. J. Exp. Physiol. 63: 39-47.

Uchitel, O., and N. Robbins (1978) On the appearance of acetylcholine receptors in denervated rat diaphragm, and its dependence on nerve stump length. Brain Res. 153: 539-548.

Vrbova, G., T. Gordon, and R. Jones (1978) Nerve-Muscle Interactions, pp. 1-233, Chapman and Hall, London.

Ware, F., A. L. Bennet, and A. R. McIntyre (1954) Membrane resting potential of denervated mammalian skeletal muscle measured in vivo. Am. J. Physiol. 173: 115-118.

Westgaard, R. H. (1975) Influence of activity on the passive electrical properties of denervated soleus muscle fibers in the rat. J. Physiol. (Lond.) 251: 683-697. 